DEVELOPMENTAL BIOLOGY, 4, 377-397 (1962)

\title{
Kinetic Experiments on the Nature of the Growth Mechanism in Oat Coleoptile Cells ${ }^{1}$
}

\author{
Peten M. Ray and Albent W. Ruesink \\ Department of Botany, University of Michigan, Ann Arbor
}

Accepted November 17, 1961

\section{INTRODUCTION}

There is rather general agreement that the enlargement of plant cells during growth is governed by irreversible expansion or stretching of the cell wall. The property of the cell wall which allows it to expand during growth has been widely called plasticity.

If wall expansion during growth resulted from the yielding of bonding forces within the cell wall under the stress exerted on them by turgor pressure, we feel it would be proper to consider that growth occurs by plastic flow. The fact that not only turgor pressure, but also cellular metabolism, is required for growth to occur must be accounted for by assuming that the plastic property of the cell wall is constantly maintained by metabolism and disappears when metabolism is inhibited.

On the other hand, it is possible that wall expansion could be due to the breaking of critical bonds in the cell wall by chemical (metabolic) action, as would be required if the wall structure involved chemical cross links between its polysaccharide units; for this reason growth would depend upon metabolism. This type of expansion would be governed not by a physical plasticity of the cell wall material, but by the rate of the reaction(s) involved in bond splitting.

In terms of the physics of viscoelastic hehavior (Mark and Tobolsky, 1950; Ferry, 1961), the alternatives just raised amount to asking whether the expansion of the cell wall is governed by a steady-flow viscosity or by a chemorheological process; in structural terms, they

${ }^{1}$ This work was supported by National Science Foundation Grant NSF G-8705. Some of the experiments were done during the tenure of a National Science Foundation Research Participation Fellowship by A. W. Ruesink. 
correspond approximately to the distinction between a linear or branched but not cross-linked polymer on the one hand, and a crosslinked macromolecular network on the other. We have previously referred to the chemorheological type of expansion as a "molecular mosaic" mechanism (Ray, 1961a,b). In our opinion it is not as yet possible to be sure whether measurements of "plasticity" of growing cell walls (Adamson and Adamson, 1958; Cleland, 1958; Heyn, 1931; Preston and Hepton, 1960; Tagawa and Bonner, 1957) measure plastic flow as opposed to an alternative mechanism of expansion.

The experiments on oat coleoptile cylinders described here were undertaken to test the question by ascertaining how rapidly the rate of growth responds to changes in the rate of metabolism. If the rate of growth is controlled by a physical plasticity which is being maintained in time by metabolism, then when the rate of metabolism is changed, the rate of growth should respond with a time constant which reflects what proportion of the plasticity is renewed or replaced through metabolic activity per unit of time. On the other hand, if the rate of growth were controlled directly by the rate of a metabolic reaction, as in a chemorheological mechanism, the response of the growth rate to changes in the rate of the growth-controlling reaction should be immediate.

It was felt that a treatment which would influence metabolic reactions quite generally and immediately would be to change the temperature. This parameter could be measured directly and would be free of the problems of permeability which chemical treatments would involve. $\Lambda$ ccordingly, the basic experiment was to determine how rapidly the rate of growth responds to changes in temperature of the tissue. In order to interpret the results more fully, experiments were performed also on the effects of cyanide and oxygen and on the response to indoleacetic acid (IAA).

\section{METHODS}

An apparatus was built to follow continuously the growth of an oat coleoptile cylinder, with precision sufficient to measure the growth which occurs in 1 minute. This consisted of a Plexiglas chamber, illustrated in Fig. 1, which was mounted on the mechanical stage of a compound microscope. Within the chamber was mounted, on a plastic spindle, a small copper-constantan thermocouple junction $(C)$, of such a size that an oat coleoptile cylinder $(D)$ could be slipped 

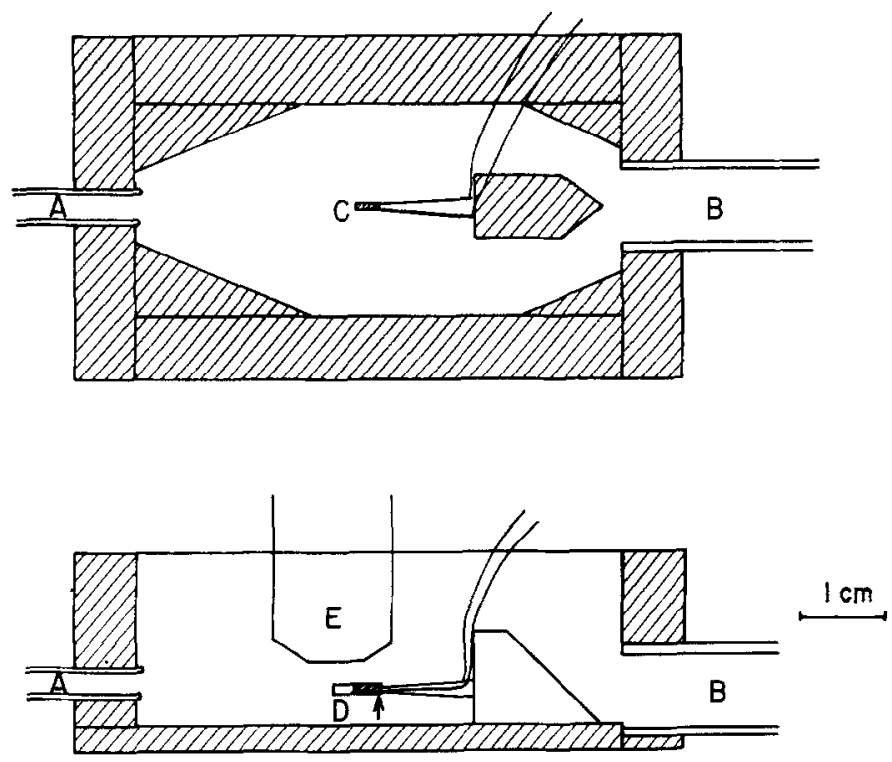

FIG. 1. Plexiglas growth chamber, top view above, side view below. Symbols explained in the text.

over it and thereby held horizontally in the chamber. One end of the tissue cylinder was tied securely with fine thread around the plastic spindle (arrow); the other end was free in the chamber. Water, auxin solution, or other treatment solution from a large reservoir flowed continuously through the chamber, entering through tube $A$ and leaving through tube $B$; the rate of inflow was regulated so that the liquid level just covered the tissue cylinder. The volume of liquid within the chamber was then approximately $2 \mathrm{ml}$, and the rate of flow approximately $25 \mathrm{ml}$ per minute.

The free end of the coleoptile cylinder was observed with a 4-mm objective lens $(E)$ and a $10 \times$ ocular containing an ocular micrometer with 100 divisions. Illumination was from a 100 -watt microscope lamp passed through a diffusing plate and green filter, and was concentrated on the free end of the section, and suitably attenuated, with condenser and iris diaphragms. The objective lens dipped into the liquid in the chamber so that water separated the lens face from the edge of the tissue; the free end of the coleoptile cylinder was cut slightly obliquely and the side with the projecting edge was mounted 
upward; these precautions ensured a clear and parallax-free image. By means of the mechanical stage, the chamber was positioned so that the end wall of a single subepidermal cell (usually an end wall which bulged out slightly beyond the general edge of the section) fell across the ocular micrometer scale; the end wall formed a sharp line whose position could be read to half a division on the scale. The progress of this line along the scale with time served to measure the growth of the coleoptile cylinder. One unit on the ocular scale was equal to $1.5 \mu$. Growth, in $3 \mathrm{mg}$ IAA per liter at $23-25^{\circ} \mathrm{C}$, of cylinders used in these experiments was 5-9 divisions per minute, depending on the cylinder, or $0.45-0.8 \mathrm{~mm}$ per hour. When the index line of the image reached the end of the ocular scale it was quickly repositioned near the beginning of the scale, using the mechanical stage, and another reading was taken; in this way growth could be followed indefinitely. In general, readings were taken once a minute.

Occasionally sections grew crooked and appeared to move sidewise under the micrometer scale. If this occurred slowly, the section was repositioned sidewise with the mechanical stage when necessary; if the section grew so crooked that the index line moved sidewise away from the micrometer scale within 5 minutes, the section was removed and the results were not considered.

The temperature of the tissue cylinder was monitored continuously with the thermocouple and a galvanometer, the cold junction being held in ice water. One degree centigrade equaled approximately 4 divisions on the galvanometer scale; the thermocouple was calibrated with solutions of known temperature after every experiment.

Change from one treatment to another was accomplished by $\mathrm{Y}$ connections in the inlet tubing just outside the chamber, so that liquid from a different reservoir could be made to start flowing through the chamber by transferring a pinch clamp from one tube to another, without disturbing the liquid level in the chamber or the microscopic image. Temperature treatments other than room temperature were obtained by immersing a reservoir in a water bath maintained at the desired temperature and passing the liquid from this reservoir through tubing submerged in a water bath, also at the desired temperature, located just before the $\mathrm{Y}$ connections on the inlet side of the chamber.

How rapidly the solution within the chamber became replaced by new solution when the pinch clamp was transferred can be judged from the fact that when transferring between solutions at different 
temperatures the temperature change in the tissue cylinder was completed within 15 seconds.

There was a slight apparent thermal contraction and expansion of the apparatus. This was minimized to $6 \mu$ per $10^{\circ} \mathrm{C}$ temperature change, by holding the Plexiglas chamber to a Plexiglas base plate by screws located at the entrance tube end, the base plate (rather than the chamber itself) being held in the mechanical stage. Thermal contraction or expansion of the apparatus was nearly complete 1 minute after solutions were changed. The growth curves shown in Fig. 2 were corrected for thermal contraction or expansion of the apparatus by following the latter at the point where the coleoptile cylinder was mounted. The correction was, however, so slight as to have no effect upon the interpretation of the results.

Part of the shrinkage observed during the first 15 seconds after lowering the temperature could not be accounted for by thermal contraction of the apparatus; it appears to be of about the magnitude that would be predicted for the tissue cylinder from the thermal coefficient of expansion of water. This restricts the interpretation of the results to times beyond the first 15 seconds after temperature transfer.

Oats of the variety Victory (Svalöf) were soaked for 2 hours, placed on moist paper, allowed to germinate for 1 day under a 25watt ruby red photographic safelight, then left for 2 days in darkness at about $26^{\circ} \mathrm{C}$. A coleoptile cylinder about $6.8 \mathrm{~mm}$ long was cut, beginning $3 \mathrm{~mm}$ from the tip, under red light. The apical end was used as the free end in the measuring chamber; cylinders were kept in distilled water $0.5-1.5$ hours at roum temperature before being mounted in the chamber. Length of the section beyond the tie thread was measured at the end of the experiment. The growth chamber was set up in a room darkened by having blinds drawn, but not totally dark.

\section{RESULTS}

\section{Effect of Temperature}

Curve 1 of Fig. 2 shows the course of growth of a coleoptile cylinder at $23^{\circ} \mathrm{C}$ in the presence of $3 \mathrm{mg} / 1$ IAA, and the result obtained when the temperature was lowered abruptly to $12^{\circ} \mathrm{C}$. The first reading after the arrow was taken 20 seconds after transfer to $12^{\circ}$ solution; by this time the coleoptile cylinder had reached the 


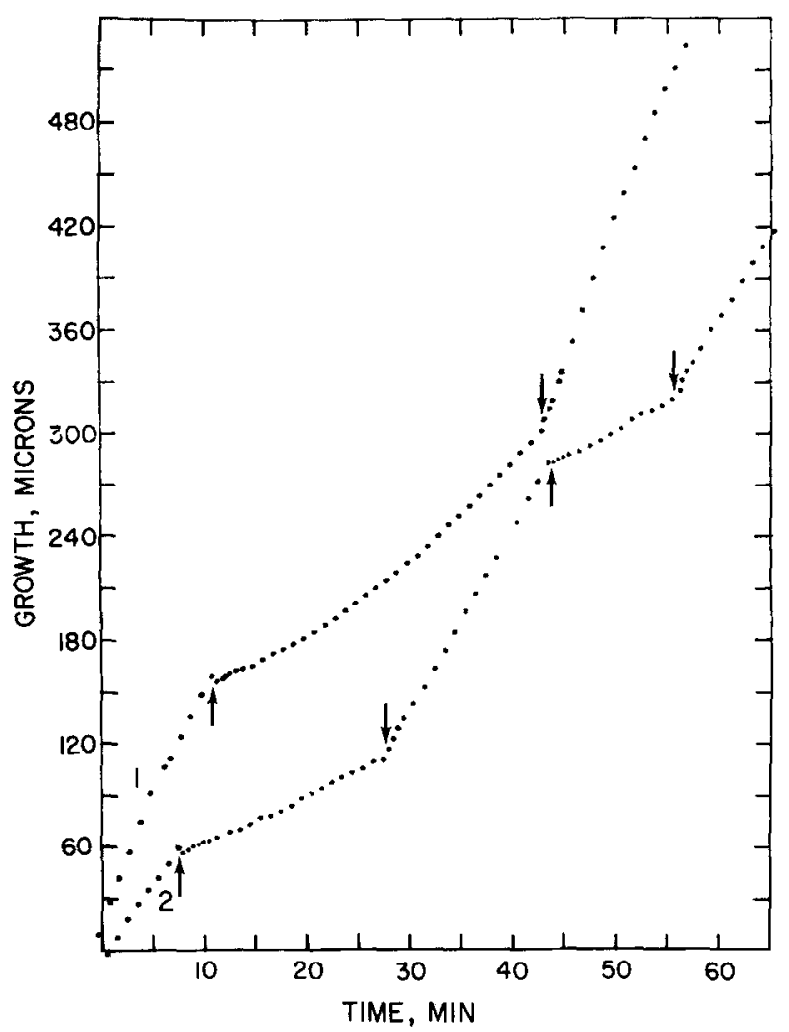

Fig. 2. Effect of changing the temperature between $23^{\circ}$ and $12^{\circ} \mathrm{C}$. At upward pointing arrows, temperature was changed from $23^{\circ}$ to $12^{\circ}$; at downward pointing arrows, from $12^{\circ}$ to $23^{\circ}$. Curve 2 is a continuation of the same experiment, ordinate and abscissa being transposed back to zero. Cylinder was $9.6 \mathrm{~mm}$ long at end of experiment; 3 ung IAA per liter was present throughuut.

final temperature. From the beginning, the rate of growth was approximately one-third that at $23^{\circ}$ and did not decline further. When the temperature was returned to $23^{\circ}$, the growth rate rose immediately to a value comparable to that prior to $12^{\circ}$ treatment. The cycle was repeated twice in the experiment shown in Fig. 2, with similar results.

That the rate of growth responds immediately, within the precision of this method of measurement, to changes in temperature has been observed repeatedly, and in no case did the rate decline further be- 
yond the degree of inhibition initially observed upon transfer to a cooler temperature. There was sometimes a tendency for the rate to increase slightly at the lower temperature, as in the first part of Fig. 2.

The growth of several coleoptile cylinders was measured at intervals of approximately $9^{\circ}$ between $2^{\circ}$ and $30^{\circ} \mathrm{C}$, starting with the lowest temperature and following growth for about 10 minutes at each temperature. The results are summarized in Table 1 . The tem-

TABLE 1

Temperature Coefficient of Coleoptile Elongation Rate ${ }^{a}$

\begin{tabular}{clll}
\hline & \multicolumn{3}{c}{$\Delta \log r / \Delta T\left(\mathrm{deg}^{-1}\right)$ at temperature interval: } \\
\cline { 2 - 4 } $\begin{array}{c}\text { Cylinder } \\
\text { no. }\end{array}$ & \multicolumn{1}{c}{$\frac{11^{\circ}}{2^{\circ}}$} & $\frac{200^{\circ}}{11^{\circ}}$ & $\frac{30^{\circ}}{20^{\circ}}$ \\
\hline 1 & 0.063 & 0.068 & 0.035 \\
2 & 0.060 & 0.055 & 0.022 \\
3 & 0.056 & 0.060 & 0.030 \\
4 & 0.065 & 0.057 & 0.032 \\
5 & 0.039 & 0.035 & 0.031 \\
Mean & 0.0566 & 0.0550 & 0.0300 \\
$Q_{\text {Ia }}$ (mean) & 3.69 & 3.55 & 2.00 \\
\hline
\end{tabular}

${ }^{a}$ The actual temperatures used in different experiments varied up to about $\pm 1^{\circ} \mathrm{C}$ from the temperatures listed. To express the results, for each temperature interval the $\log$ of the ratio of elongation rates at the two temperatures was divided by the actual difference in temperature, giving $\Delta \log v / \Delta T$. The $Q_{10}$ was computed as antilog $(10 \cdot \Delta \log v / \Delta T)$.

perature coefficient between $2^{\circ}$ and $11^{\circ}$ was similar to that between $11^{\circ}$ and $20^{\circ}$. Between $20^{\circ}$ and $30^{\circ}$ the temperature coefficient was conspicuously lower. At $30^{\circ}$ or above, the rate of growth fell off within a few minutes to a value equal to or less than that at $20^{\circ}$ or $23^{\circ}$; the temperature coefficient given in Table 1 is for the initial (maximum) rate at $30^{\circ}$.

The temperature dependence found for coleoptile cylinder growth resembles that of many biological processes (Johnson et al., 1954), including growth of intact plants (e.g., Lehenbauer, 1914). The temperature coefficient between $2^{\circ}$ and $20^{\circ}$ corresponds to an apparent activation energy of about $20,000 \mathrm{cal} / \mathrm{mole}$. This value falls within the range typical of enzyme-catalyzed chemical reactions (Sizer, 1943), hence it might well reflect the temperature dependence 
of metabolic reactions upon which growth depends. The immediate response of the growth rate to a change in temperature would be consistent with the conclusion that the rate of growth is controlled directly by the rate of a metabolic reaction or reactions, as in a chemorheological process.

However, if growth rate were controlled by a physical plasticity (viscosity), this property would be temperature dependent. The initial response of growth rate to change in temperature would then reflect the (physical) temperature coefficient of plasticity. Were the initial response a purely physical effect, then, if it be accepted that plasticity must be maintained in time by metabolism, the fact that lowering the temperature has slowed down metabolic processes must result in a further decline in the growth rate, subsequent to the initial effect, and reflecting the dependence of plasticity upon metabolism.

In order to assess fully the fact that no further decline in growth rate occurred subsequent to the initial effect, one must determine by an independent method at least a maximum value for the time required for a change in rates of metabolic processes to show itself as an effect on the growth rate. Then one would know whether the temperature effect on metabolism in experiments like that of Fig. 2 should have exerted an effect on the growth rate within the period of treatment at $12^{\circ}$, or not. To decide this, expcriments with cyanide, and with deprivation of oxygen, were undertaken.

\section{Effect of Cyanide}

When coleoptile cylinders were transferred from $3 \mathrm{mg} / \mathrm{l}$ IAA to IAA plus $10^{-3} M \mathrm{KCN}$, the half-time (time for half the final change in rate to occur) for the inhibitory response was about 3 minutes at $23^{\circ} \mathrm{C}$, as shown in curve 2 of Fig. 3. The speed of response depended upon the KCN concentration, the half-time being about 5 minutes with $10^{-4} M \mathrm{KCN}$ (curves 1 and 3, Fig. 3). Upon transfer back to IAA without $\mathrm{KCN}$, the inhibition became completely reversed after a lag period of a few minutes (Fig. 3).

The effect of cyanide was tested also at $12^{\circ} \mathrm{C}$ (Fig. 4). The response was similar but slightly slower, the half-time for inhibition by $3 \times 10^{-4} M \mathrm{KCN}$ being $6-7$ minutes.

The speed of response appears to depend primarily upon the rate 


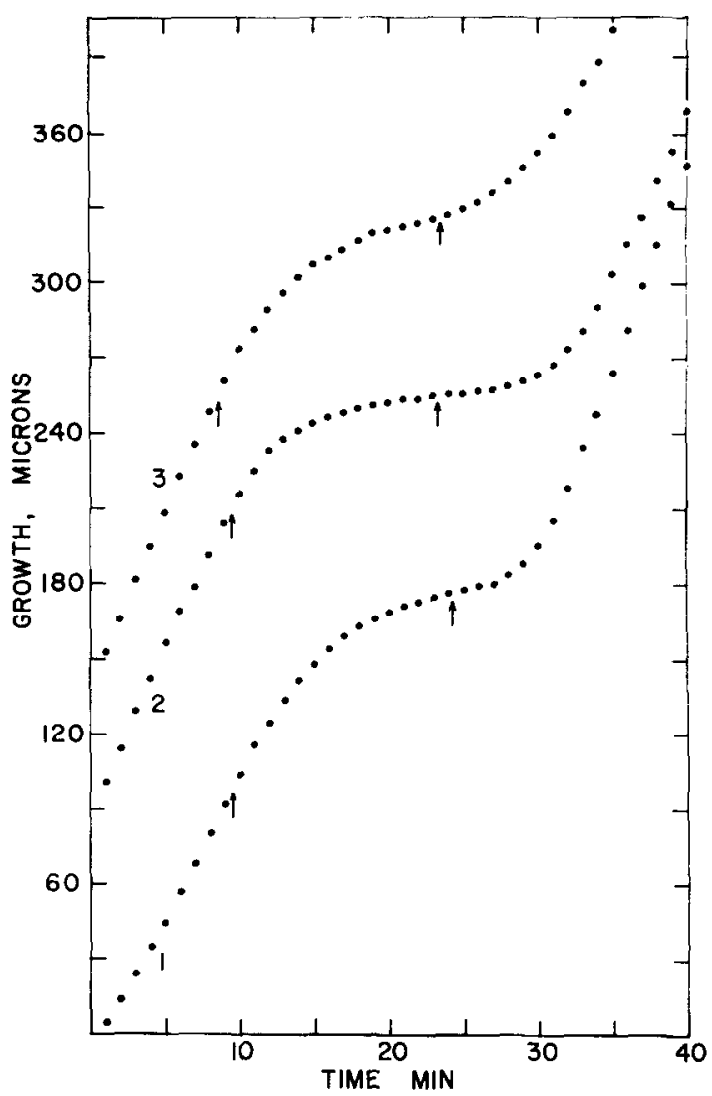

FIg. 3. Effect of $\mathrm{KCN}$ at $23^{\circ} \mathrm{C}$. The curves show successive trials with the same cylinder, curves $I$ and 3 being with $10^{-4} M \mathrm{KCN}$ and curve 2 with $10^{-3} M \mathrm{KCN}$. At the first arrow the cylinder was transferred from $3 \mathrm{mg} / \mathrm{l} \mathrm{IAA}$ to IAA plus $\mathrm{KCN}$; at the second arrow it was transferred back to IAA alone. The third trial was made to show that the difference between curves 1 and 2 was not due to a change in propreties of the cylinder during the experiment. Cylinder was $8 \mathrm{~mm}$ long.

of diffusion of cyanide into the tissue. This is indicated by the fact that the half-time for inhibition depended upon $\mathrm{KCN}$ concentration. The length of the lag phase preceding recovery, after the tissue was transferred back to IAA alone, also depended noticeably upon the $\mathrm{KCN}$ concentration previously used (Fig. 3). This finding suggests 


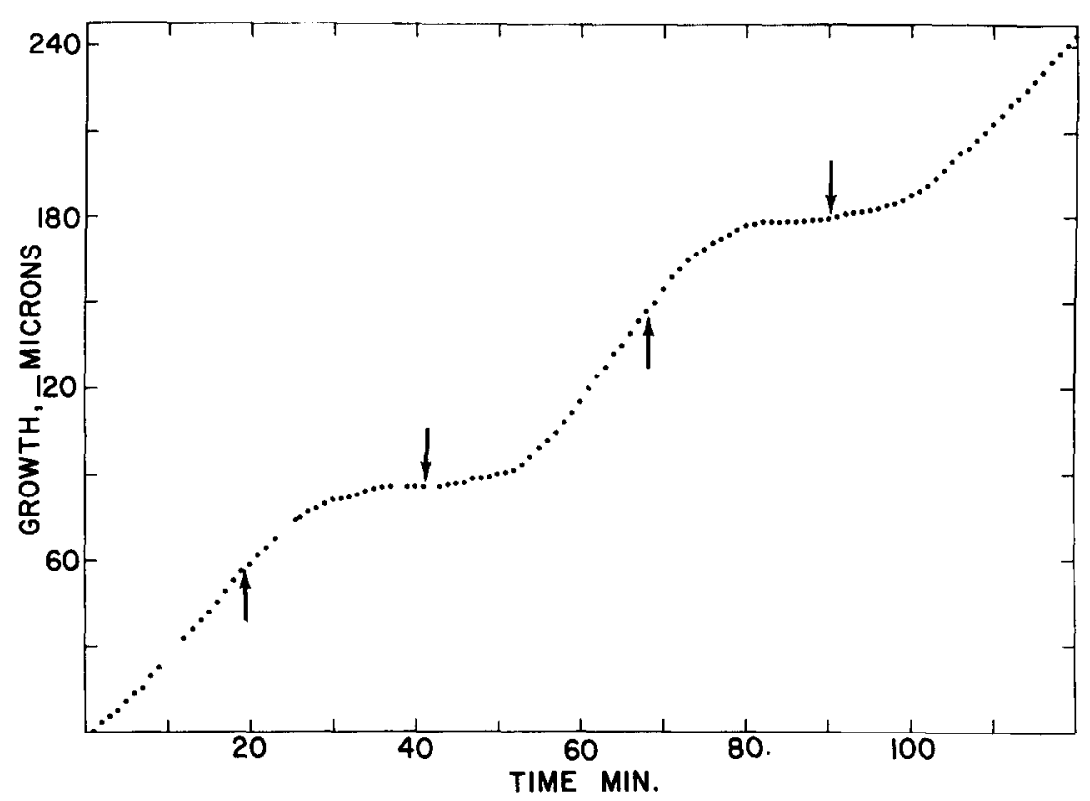

Fig. 4. Effect of $3 \times 10^{-1} \mathrm{M} \mathrm{KCN}$ at $12^{\circ} \mathrm{C}$. Cyanide was added at the upward-pointing arrows and removed at the downward-pointing arrows; $3 \mathrm{mg} / \mathrm{l}$ IAA was present throughout. Cylinder was $8.7 \mathrm{~mm}$ long.

that the lag phase represents the time required for the cyanide concentration within the tissue to fall, by diffusion, below saturation of the inhibited enzyme(s).

The results with cyanide prove that response of the growth rate to changes in rate of metabolism is rapid, and certainly would have appeared within the periods of $12^{\circ} \mathrm{C}$ treatment used in the experiment of Fig. 2. Since the inhibition of growth caused by lowering the temperature appeared entirely within the first 20 seconds, and no further decline in growth rate occurred, it seems necessary to conclude that inhibtion of metabolic reactions by lowering the temperature had exerted its effect on the growth rate within 20 seconds. Therefore, it appears that the metabolic time constant for any physical property of the cell wall which might govern growth rate is so short that growth is essentially controlled by the rate of metabolic process(es). This is tantamount to a chemorheological growth mechanism.

One further qualification must be added on the basis that one does 
not know in what manner the presumptive plastic property of the cell wall may be dissipated when metabolism is not acting to maintain it. Evidence presented by Cleland and Bonner (1956) suggested that the occurrence of cell wall expansion was the manner in which an increase in "plasticity" became expended. If this were the case, the above argument appears to apply without difficulty. But suppose, on the other hand, that the plastic property were being dissipated by a metabolic reaction, for example demethylation of polyuronic acid carboxyl groups according to the pectin hypothesis of auxin action (cf. Adamson and Adamson, 1958). In this case the metabolic growth response to temperature would depend on the relative values of the temperature coefficients of reactions which increase wall plasticity as compared with those which decrease it. It is possible, but highly improbable, that these two classes of reactions would have identical temperature coefficients, so that the balance between rates of increase and decrease in plasticity would not be altered by changing the temperature. Then the response of growth to temperature would have to be attributed entirely to physical effect of temperature on plasticity, not to metabolism at all. This would be in complete disharmony with the generally prevailing view that the strong dependence of growth rate upon temperature is an indication of the metabolic basis of growth. While we do not regard this possibility as at all likely, we would like to have a test of it.

The results of inhibiting metabolism by means other than altering the temperature provide a test, which is, however, imperfect because of diffusion problems. In rclation to the question just raised, the results of depriving the tissue of oxygen are especially interesting, and will now be described. The question will be considered further in the Discussion.

\section{Effect of Oxygen}

In order to study the effect of oxygen on growth, the thermocouple junction was removed from the base of the chamber and mounted to one side so that the junction was immersed in the test solution to measure its temperature, and the coleoptile cylinder was mounted instead on a No. 23 syringe needle fixed horizontally in a plastic block in a manner similar to that illustrated for the thermocouple junction in Fig. 1. The base of the needle was bent upward out of the chamber and connected so that prepurified grade $(>99.996 \%)$ nitro- 
gen could be passed through the coleoptile cylinder to gas it. The chamber was covered with a plastic cover containing a hole to admit the objective lens mount, and a partial seal between these parts was obtained by passing the objective lens mount through a piece of rubber dam which rested upon the chamber cover all the way around the hole. By appropriate connections nitrogen was passed in continuously through the exit tube $B$, and escaped around the edges of the chamber cover. The coleoptile cylinder was thereby forced to obtain all its $\mathrm{O}_{2}$ from the solution in which it was immersed. It was gassed internally with nitrogen for only about half a minute, at the time of transfer from the solution containing air, to a solution which was gassed, in the reservoir, continuously with nitrogen.

After a coleoptile cylinder was transferred from aerated to nitrogen-gassed solution, as shown by the first arrow in Fig. 5, 4-5 minutes elapsed before any noticeable effect on the growth rate developed. Then the growth rate fell rapidly to a much inhibited value. Upon transfer back to the solution containing air (second arrow), the response was extremely rapid, the original growth rate being recovered completely within 3 minutes. This result was repeated almost exactly upon a second trial, as shown in Fig. 5.

The quickness of the response involved in recovery as compared with inhibition is just the opposite of that found with cyanide. Since with the oxygen effect, inhibition results from outward diffusion and recovery results from inward diffusion into the tissue, also opposite to the situation with cyanide, we interpret these kinetics as indicating that the speed of the oxygen response is limited primarily by the diffusion of $\mathrm{O}_{2}$, the oxygen concentration provided by an aerated solution exceeding considerably that needed for maximum growth rate.

Complete recovery of the growth rate in 3 minutes when oxygen was resupplied indicates that, if steady-flow viscosity governed the elongation rate, the entire response of this property to increase in the rate of respiration would have to be completed within 3 minutes, and in fact within a shorter time since the speed of the response was diffusion limited. This again points toward the view that the rate of growth is essentially controlled by the rate of a metabolic process, and favors the previous conclusion that elongation is a chemorheological process rather than a plastic flow. 


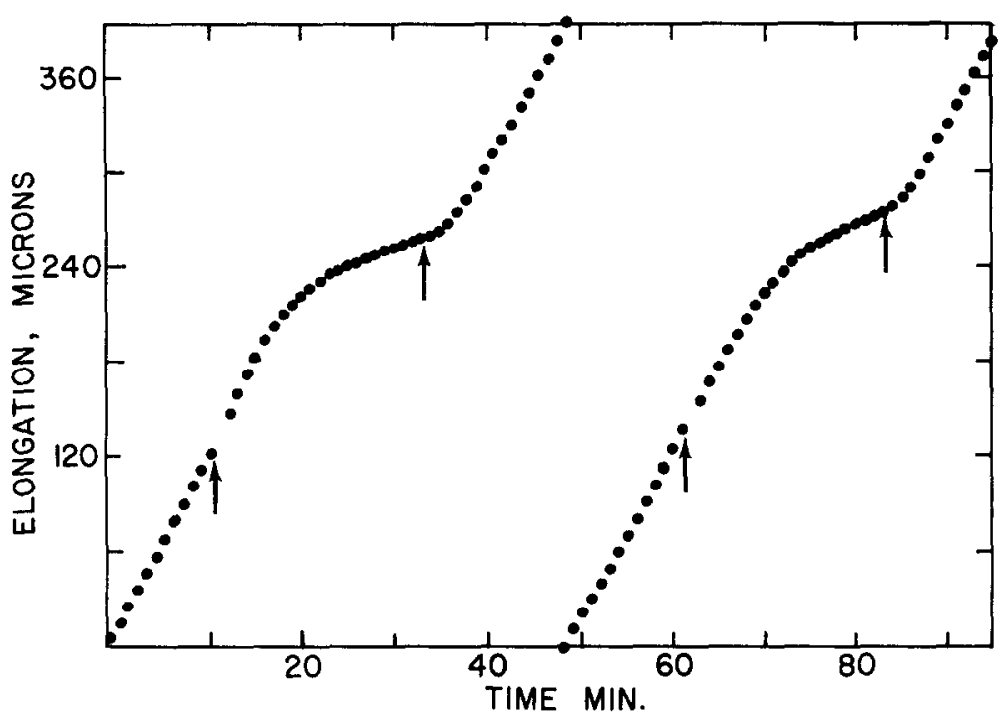

Fic. 5. Effect of depriving coleoptile cylinder of oxygen $\left(23^{\circ} \mathrm{C}\right)$. At first and third arrows, the cylinder was transferred from aerated $3 \mathrm{mg} / \mathrm{l}$ IAA to IAA solution gassed with $\mathrm{N}_{2}$; at second and fourth arrows, it was transferred back to aerated IAA solution. Ordinate was transposed downward at 48 minutes. Cylinder was $9.5 \mathrm{~mm}$ long.

Effect of Auxin

Figure 6 shows the response of a coleoptile cylinder to transfer from water to $3 \mathrm{mg} / 1 \mathrm{IAA}$ al $23^{\circ} \mathrm{C}$ (first arrow). The slow rate of growth which occurs in water persists for 7-17 minutes, depending on the cylinder, and then a sudden rise to the more rapid growth rate typical of cylinders in auxin, occurs. This result has been obtained in many experiments. Yet it has been stated (Bonner and Foster, 1955) that the growth response to coleoptile cylinders to auxin is immediate; we feel that this view may be based on methods of measurement not sufficiently precise to detect the lag phase.

Using a method somewhat like the present one, Köhler (1956) observed a lag of about 10 minutes in the response of coleoptile cylinder elongation rate to auxin.

It seems interesting and possibly significant that the time required for complete response of the growth rate to IAA is approximately 


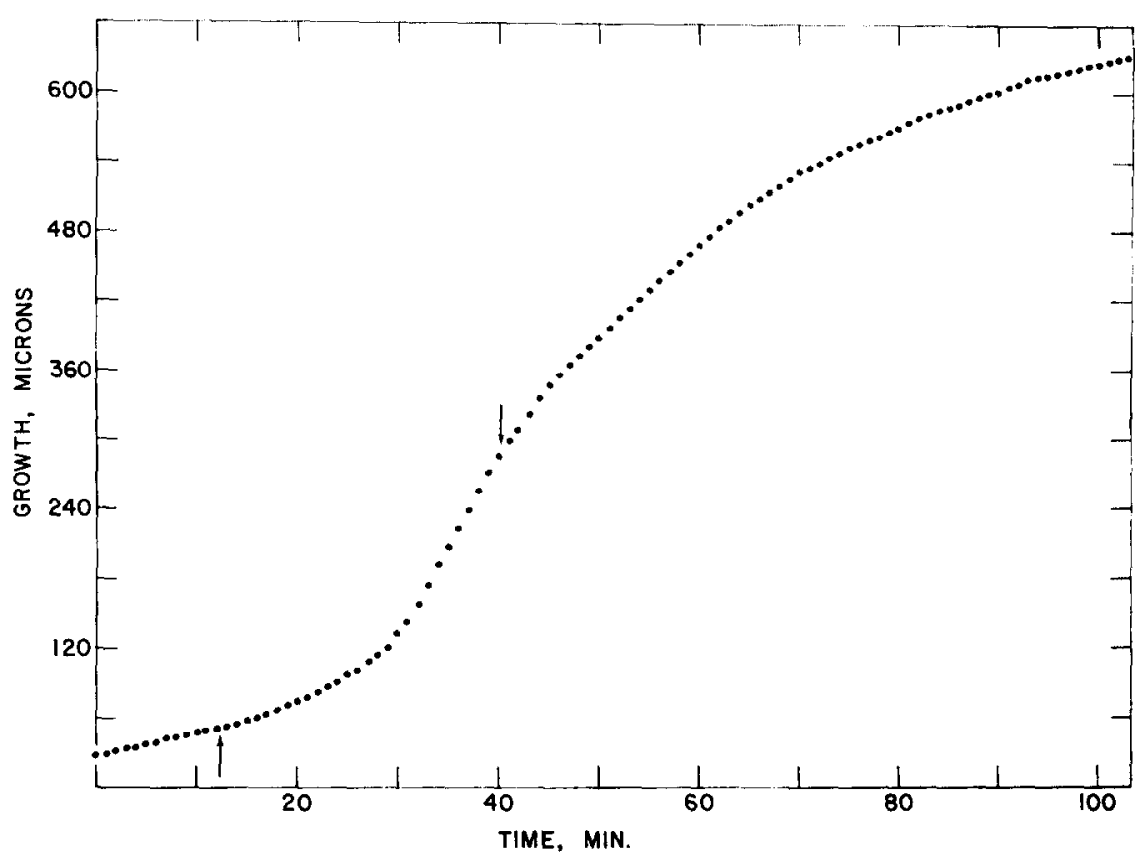

Fig. 6. Effect of IAA. Cylinder was transferred from water to $3 \mathrm{mg} / 1 \mathrm{IAA}$ at first arrow, back to water at second arrow. Cylinder was $8 \mathrm{~mm}$ long.

the same as was found by Sweeney (1941) and Sweeney and Thimann (1942) for the maximum response of protoplasmic streaming rate to auxin, in oat coleoptile cells.

When a coleoptile cylinder is transferred from auxin solution back to water, as at the second arrow in Fig. 6, a gradual decline of the growth rate to that typical of tissue in water occurs, not reaching completion before about 40 minutes.

We examined the influence of temperature on the lag phase in response to auxin. This was done by determining the length of the lag phase at $23^{\circ}$ or $13^{\circ} \mathrm{C}$ for a number of coleoptile cylinders, since the time required for return to the water rate on transfer back to water was so long that the experiment could not practicably be done with a single cylinder at the two temperatures.

Typical results at $23^{\circ}$ and $13^{\circ} \mathrm{C}$ are shown in Fig. 7 , in which the arrows indicate the time of transfer from water to $3 \mathrm{mg} / \mathrm{l}$ IAA. Table 2 summarizes the data obtained, in terms of the time for 


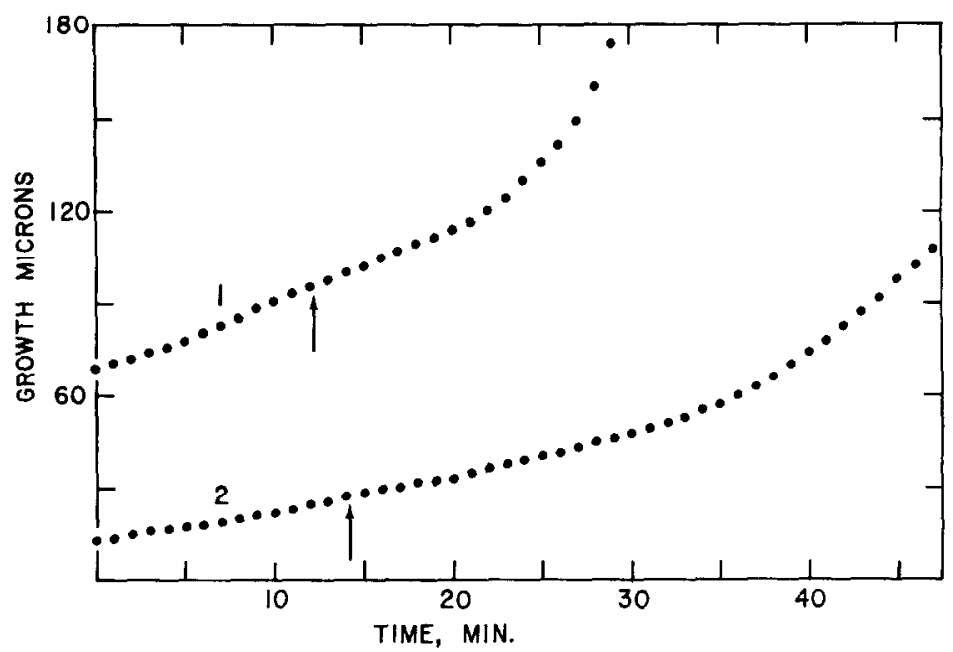

FIG. 7. Effect of temperature on the lag phase in response to IAA. Curve 1 , cylinder at $23^{\circ} \mathrm{C}$; curve 2 , at $13{ }^{\circ} \mathrm{C}$. Transferred from water to $3 \mathrm{mg} / 1 \mathrm{IAA}$ at the arrow.

half-maximum growth response. Although as noted previously there is considerable variation from cylinder to cylinder, the data indicate rather certainly that the lag phase was longer at $13^{\circ}$ than at $23^{\circ}$, apparently being about twice as long at the lower temperature.

TABLE 2

Length of Lag Period in Response to 3 mg/L IAA

\begin{tabular}{cccccccc}
\hline Temperature & & \multicolumn{4}{c}{ Lag periods found in single trials $(\min )^{4}$} & & Mean \pm S.D. \\
\hline $23^{\circ} \mathrm{C}$ & 14 & 10 & 14 & 12 & 15 & 11 & $12.6 \pm 1.5$ \\
$13^{\circ} \mathrm{C}$ & 24 & 23 & 26 & 32 & 34 & -- & $27.8 \pm 4.1$
\end{tabular}

${ }^{a}$ Time for half the final increase in growth rate to occur.

In separate experiments the lag effect observed with $3 \mathrm{mg} / \mathrm{I}$ IAA was compared with that obtained using $30 \mathrm{mg} / \mathrm{l}$ IAA. At neither temperature did the length of the lag phase depend conspicuously upon IAA concentration (Table 3).2 This indicates that the length of the lag phase is not determined primarily by the rate of penetra-

${ }^{2}$ For reasons not understood, the lag periods in this experiment were somewhat shorter than normal at both temperatures. 
tion of auxin into the tissue, and hence shows that the effect of temperature on the lag phase is not due to a difference in rate of penetration.

TABLE 3

EFfect of IAA Concentration on Lag Period

\begin{tabular}{ccc}
\hline $\begin{array}{c}\text { Concentration } \\
\text { of IAA } \\
(\mathrm{mg} / \mathrm{A})\end{array}$ & $24^{\circ} \mathrm{C}$ & Lag period (min) a at \\
\hline 3 & $7 \pm 1(3)$ & $20 \pm 3(4)$ \\
30 & $8 \pm 1(3)$ & $17 \pm 2(6)$ \\
\hline
\end{tabular}

a Figures in parentheses show the number of trials in each treatment; numbers after \pm give average deviation, to nearest digit.

We interpret the effect of temperature on the lag phase as indicating that IAA does not exert a direct effect upon the process which controls the rate of growth of the coleoptile cylinder, for example as a cofactor for the rate-controlling metabolic reaction. The results suggest instead that IAA acts upon some property or process of the cell which indirectly influences the growth-controlling process by way of intermediary temperature-sensitive metabolic reactions. For example, auxin could cause a change in the rate of some metabolic reaction within the cell which, via a biochemical pathway, eventually changes the concentration of a substrate of the growth rate-controlling reaction; or it could promote synthesis of an enzyme which catalyzes the growth reaction. The idea that auxin acts on growth in some such indirect fashion was discussed recently by Carr and $\mathrm{Ng}$ (1959).

\section{DISCUSSION}

The older literature records some interest in how quickly the rate of plant growth responds to changes in temperature. True (1895) concluded that earlier findings as well as his own experiments supported the view that the response of growth rate to change in temperature is immediate, except when cold treatments of many hours, or supraoptimal temperatures, are given. We may note also that Barlow and Hancock (1959) recently reported immediate adjustment of the growth rate of wheat coleoptile cylinders to changes in temperature. The growth measurements referred to were made at intervals of 15 minutes or longer; hence the present experiments support the earlier conclusion with considerable refinement. 
We concluded above that the immediate effect of temperature on the growth rate of coleoptile cylinders in all probability involves the temperature dependence of metabolic processes which contribute to growth, and is not due merely to temperature dependence of a physical property (steady-flow viscosity, or plasticity). Since this question is crucial to an assessment of the growth mechanism, we shall note here one further way in which it may be examined.

In general it appears that with plastic materials which possess a much greater steady-flow viscosity than ordinary liquids, ${ }^{3}$ and in which viscosity is as strongly dependent on temperature as was found above for elongation rate, the temperature dependence of viscoelastic properties diverges substantially from the Arrhenius form $\left(\mathrm{A} \exp \left[\Delta H_{a} / R T\right]\right)$. The viscoelastic behavior of a wide variety of materials has been found (Ferry, 1961) to follow the equation ${ }^{4}$

$$
\log \left(\frac{\eta}{\eta_{s}} \cdot \frac{T_{s} \rho_{s}}{T_{\rho}}\right)=-\frac{c_{1}\left(T-T_{s}\right)}{c_{2}+T-T_{s}}
$$

which is called the "WLF equation" after its discoverers (Williams, Landel, and Ferry, 1955). In this relationship the temperature coefficient $\left(Q_{10}\right)$ increases rather rapidly as the temperature is lowered, in contrast with the Arrhenius equation by which the $Q_{10}$ varies only slightly with temperature. For example, if the ratio of steady-flow viscosities at $11^{\circ}$ and $21^{\circ} \mathrm{C}$ were 3.5 , like the $Q_{10}$ for coleoptile elongation rate in this temperature range, then according to the WLF equation (with $T_{s}$ chosen as $254^{\circ} \mathrm{K}$ so as to give the observed temperalure dependence between $11^{\circ}$ and $21^{\circ}$ ), the ratio of viscosities at $1^{\circ}$ and $11^{\circ} \mathrm{C}$ should be about 4.4 , and hence a $Q_{10}$ of about 4.4 should be observed for elongation rate in the latter temperature range if the WLF equation is being followed.

The results in Table 1 rather definitely indicate that the temperature coefficient for elongation rate in the interval $2-11^{\circ} \mathrm{C}$ is not substantially greater than in the interval $11-20^{\circ}$. Therefore, between

${ }^{3}$ This would include the oat coleoptile cell wall: it may be calculated that the apparent steady-flow viscosity of the cell wall material of a coleoptile cylinder elongating $10 \%$ per hour would be of the order of $3 \times 10^{12}$ poises.

${ }^{4} \eta$, steady-flow viscosity; $T$, absolute temperature; $\rho$, density; $c_{1}$ and $c_{2}$, constants whose values are 8.86 and 101.6 , respectivcly, when the "characteristic temperature" $T_{*}$ (at which viscosity and density are $\eta_{*}$ and $\rho_{*}$ ) is chosen in a suitable manner. 
$2^{\circ}$ and $20^{\circ}$ the immediate response of elongation rate to temperature appears to conform more closely with the Arrhenius equation (typical of chemical processes) than with the WLF equation. And on the other hand, the drop in temperature coefficient between 20 and $30^{\circ} \mathrm{C}$ is too great to be consistent with the WLF equation, which would predict a $Q_{1}$ of about 3.0. Thus the immediate dependence of growth rate on temperature deviates from the WLF equation in opposite senses above $20^{\circ}$ and below $11^{\circ}$, in a manner which precludes looking for an explanation simply in inaccuracies in the choice of the constants used.

Although it cannot of course necessarily be assumed that steadyflow viscosity of the cell wall material should obey closely the WLF equation, in the absence of evidence to the contrary it at least seems probable that the general type of temperature dependence of viscoelastic properties predicted by the equation should be expected. These considerations provide, therefore, additional grounds for believing that the immediate response of elongation rate to change in temperature is not due largely to temperature dependence of a physical property, but arises from the influence of temperature on metabolic processes involved in growth. It seems necessary to conclude that the growth mechanism has the character of a chemorheological process rather than a plastic flow. ${ }^{5}$

With this conclusion in mind it is of interest to consider the types of molecular processes which may be involved in bringing about cell enlargement. If primary chemical cross links between cell wall macromolecules, as illustrated in a recent model of cell wall structure (Preston and Hepton, 1960), existed in numbers sufficient to unite the macromolecules into a network structure, irreversible expansion would require that either cross links or polymer strands be severed and that new cross links be formed in unstrained configurations (Tobolsky, 1956, 1960). A linear (not cross-linked) polymer can also behave mechanically as a network structure because of secondary associative forces between molecules (Ferry, 1961), due, for example,

${ }^{5}$ The term most frequently employed for chemorheological behavior is "chemical stress relaxation"; this refers to chemically caused changes in stress at constant strain. Chemically induced extension under constant load, which most ncarly corresponds with what we conclude to be the mechanism of extension growth, can be called "chemical creep" (see Tobolsky, 1960). 
to hydrogen bonding, electrostatic forces, crystallites, etc., as in gels. Here it seems possible that introduction of new polymer molecules through biosynthesis could alter the intermolecular forces in the existing network and thereby bring about expansion.

A third possibility is that, simply because of the length of the polymer molecules, coupling of strands by entanglement with one another creates an "entanglement network" which dominates mechanical behavior. The steady-flow viscosity of such a system is governed by slippage at entanglement coupling points. It would be possible to increase the rate of extension substantially by a process which severed polymer strands at or between entanglement coupling points. We raise this type of model to illustrate the point that a chemorheological process could accelerate and hence govern the expansion of a system which nevertheless has a finite steady-flow viscosity. Hence, the present experiments do not necessarily show that the cell wall has a true network structure.

We hope that these ideas may stimulate other lines of inquiry into the biophysical basis of plant cell enlargement.

\section{SUMMARY}

A method was devised for following the growth rate of oat coleoptile cylinders with sufficient precision to measure the growth that occurred in 1 minute; the solution treating the section could be completely replaced with a different solution within 15 seconds. It was found that response of the elongation rate to changes in temperature was complete within 20 seconds, with a $Q_{10}$ of about 3.5 in the temperature range $2-23^{\circ} \mathrm{C}$, and that response to treatment with cyanide, or to treatment with oxygen when the tissue had been deprived of it, was completed in a few minutes. The results are interpreted as indicating that the rate of elongation is controlled directly by the rate of a metabolic reaction or reactions rather than by a physical property like steady-flow viscosity, and hence that the growth mechanism has the character of a chemorheological process as opposed to a plastic flow.

The growth rate of oat coleoptile cylinders becomes promoted, after auxin is added, only after a lag of about $10-15$ minutes at $23^{\circ} \mathrm{C}$. This lag is not determined primarily by the rate of penetration of auxin into the tissue; it is approximately twice as long at $13^{\circ} \mathrm{C}$. This is 
considered to indicate that the action of auxin is not directly upon the growth-controlling reaction, but affects the latter indirectly via temperature-sensitive metabolic pathways.

\section{REFERENCES}

Adamson, D., and Adamson, H. (1958). Auxin action on coleoptiles in the presence of nitrogen and at low temperatures. Science 128, 532-533.

Barlow, H. W. B., and Hancock, C. R. (1959). Studies on extension growth in coleoptile sections. III. The interaction of temperature and $\beta$-indolylacetic acid on section growth. J. Exptl. Botany 10, 157-168.

Bonner, J., and Foster, R. J. (1955). The growth-time relationships of the auxin-induced growth in Avena coleoptile sections. J. Exptl. Botany 6, 293-302.

Carr, D. J., and Ng, E. K. (1959). Residual effects of auxin, chelating agents and metabolic inhibitors in cell extension. Australian J. Biol. Sci. 12, 373-387.

Cleland, R. (1958). A separation of auxin-induced cell wall loosening into its plastic and elastic components. Physiol. Plantarum 11, 599-603.

Cleland, R., and Bonner, J. (1956). The residual effect of auxin on the cell wall. Plant Physiol. 31, 350-354.

FerRY, J. D. (1961). "Viscoelastic Properties of Polymers." Wiley, New York.

Heyn, A. N. J. (1931). Der Mechanismus der Zellstreckung. Rec. trav. botan. néerl. 28, 113-244.

Johnson, F. H., Eyring, H., and Polissar, M. J. (1954). "The Kinetic Basis of Molecular Biology." Wiley, New York.

KöHLER, D. (1956). Ùber die Beziehungen zwischen der Länge von Haferkoleoptilen und der Wachstumsgeschwindigkeit ihrer isolierten Ausschnitte. Planta 47, 159-164.

Lehenbauer, P. A. (1914). Growth of maize seedlings in relation to temperature. Physiol. Researches 1, 247-288.

Mark, H., and Toвolsky, A. V. (1950). "Physical Chemistry of High Polymeric Systems," 2nd ed. Interscience, New York.

Preston, R. D., and Hepton, J. (1960). The effect of indoleacetic acid on cell wall extensibility in Avena coleoptiles. J. Exptl. Botany 11, 13-27.

Ray, P. M. (1961a). Problems in the biophysics of plant cell growth. In "Plant Growth Regulation," pp. 381-385. Iowa State Univ. Press, Ames.

RAY, P. M. (1961b). Hormonal regulation of plant cell growth. In "Control Mechanisms in Cellular Processes" (D. M. Bonner, ed.), pp. 185-212. Ronald, New York.

Sizer, I. W. (1943). Effects of temperature on enzyme kinetics. Advances in Enzymol. 3, 35-62.

SwEENEY, B. M. (1941). Conditions affecting the acceleration of protoplasmic streaming by auxin. Am. J. Botany 29, 700-702.

Sweeney, B. M., and Thimann, K. V. (1942). The effect of auxin on protoplasmic streaming. III. J. Gen. Physiol. 25, 841-854.

Tagawa, T., and Bonner, J. (1957). Mechanical properties of the Avena coleoptile as related to auxin and to ionic interactions. Plant Physiol. 32, 207-212. 
Toвolsky, A. V. (1956). Stress relaxation studies of the viscoelastic properties of polymers. J. Appl. Phys. 27, 673-685.

Toвolsky, A. V. (1960). "Properties and Structure of Polymers." Wiley, New York.

True, R. H. (1895). On the influence of sudden changes of turgor and temperature on growth. Ann. Botany 9, 365-402.

Williams, M. L., Landel, R. F., and Ferry, J. D. (1955). The temperature dependence of relaxation mechanisms in amorphous polymers and other glassforming liquids. J. Am. Chem. Soc. 77, 3701-3707. 